\title{
Photoionization and Photoabsorption Cross Section in Ionosphere
}

\author{
Sura I. Gburi \\ ${ }^{1}$ Department of Astronomy and Space, Collage of Science, University of Baghdad
}

\begin{abstract}
This paper is devoted to a critical review of photoabsorption cross sections and photoionization for molecules and elements of astrophysical interest at wavelengths less than 1200 angstrom $(\AA)$. The photoabsorption cross section and photoionization cross sections for element oxygen $(\mathrm{O})$ and molecules oxygen (O2), nitrogen (N2), hydrogen (H2), methanol (CH4), water (H2O), Dual-dioxide (CO2), Omnidirectional dioxide (CO) have been measured in the wavelength range 60-1200 $\AA$. The result founded that the distributions of all molecules are appeared at photoabsorption cross section but not all molecules have photoionization cross section, and it related that the CO2 molecules have the both in Photoabsorption and photoionization cross section. Also this review contains a complete set of cross-section-versus-wavelength values for each molecule; the prepared figures are used to compare the results of several determinations such as behaviors of molecules with wavelength, ratio of number molecules in both photoionization and photoabsorption and the maximum value of all molecules which founded is $\mathrm{CO}=99 * 1018 \mathrm{~cm} 2$ at $\lambda=949$.
\end{abstract}

Keyword: ionosphere, Photoionization cross section, photoabsorption cross section

\section{Introduction}

The starting point in all ionospheric calculations must be the interaction of solar radiation (such as extreme ultraviolet radiation (EUV) which is between wavelength $100 \AA<\lambda<$ $1200 \AA$ ) and soft $\mathrm{x}$-ray radiation which is wavelength less than $(\lambda<100 \AA))$ with the atmospheric atoms and molecules [1]. Molecular photoionization and photoabsorption processes are fundamental importance [2] and find application in large number of scientific contexts, including studies in aeronomy, astrophysics, planetary sciences, and radiation chemistry, physics, and biology [3]. Workers in these disciplines require reliable absolute cross sections for total photoionization and photoabsorption over wide spectral ranges particularly for use in modeling studies [4].the first review for molecules published by K. Watanabe in 1958, at ultra-wavelength cross section depended on data from rocket [5]. After that many experiment rockets injection to the space to study the atmosphere of earth. In this research studied the distribution of some of molecules at Photoionization cross section, photoabsorption cross section, this of course, first requires knowledge of the solar flux versus wavelength [6]. Than compering between the molecules value at Photoionization cross section, photoabsorption cross section.

\section{Theory}

From the observational knowledge of ionosphere, the following positive ions must be considered: $\mathrm{H}+\mathrm{He}+$, $\mathrm{N}+, \mathrm{N} 2+, \mathrm{O}+, \mathrm{O} 2+, \mathrm{NO}+\ldots . .$. etc. [1] wherever it should be note that metallic ions are not present in whole ionosphere, $\mathrm{H}+$ and $\mathrm{He}+$ occur in the upper part of ionosphere above the $\mathrm{F} 2$ peak , $\mathrm{O} 2+, \mathrm{O}+$ and $\mathrm{NO}+$ are the essential ionic constituents of the $\mathrm{D}, \mathrm{E}$, and $\mathrm{F}$ regions and $\mathrm{N}+$ and $\mathrm{N} 2+$ are minor ions with maximum concentrations in $\mathrm{F}$ region, these ions such as $\mathrm{N}^{+}, \mathrm{N}_{2}^{+}, \mathrm{O}^{+}, \mathrm{O}_{2}^{+}$and $\mathrm{NO}^{+}$consider as basic ions in ionosphere reactions.[2]

The absorption cross section and densities are known with sufficient precision as far as the order of magnitude is concerned. The photoionization occur at specific wavelength depends on these equations[1]

$$
\begin{aligned}
& N_{2}+h v(\lambda<796 A) \rightarrow N_{2}^{+}+e \ldots \ldots \\
& N_{2}+h v(\lambda<510 A) \rightarrow N+N^{+}+e \\
& N_{2}+h v(\lambda<825 A) \rightarrow N^{+}+e \ldots \ldots \\
& O_{2}+h v(\lambda<910 A) \rightarrow O^{+}+e \ldots \ldots \\
& O_{2}+h v(\lambda<1026 A) \rightarrow O_{2}^{+}+e \ldots \ldots . . .
\end{aligned}
$$

A simplified photoionization process definition is shown in equation (6), which a EUV radiation strips electrons from neutral atoms which absorb the energy of a photon provided by the quantity hc/ $\lambda$, where $h$ is the Plank constant $6.62 \times h$ 10-34 J.s, c the velocity of light, and $\lambda$ the length of the incident electromagnetic wave, as represented by the equation:[7]

$$
\mathrm{a}+\frac{h c}{\lambda} \rightarrow a^{+}+e^{-}
$$

Where $\mathrm{a} \mathrm{a}^{+}$and $\mathrm{e}^{-}$represent neutral atom, a positive ion, and the free electron respectively. The amount of energy required for the ionization of the different components of the atmosphere. This energy is expressed in electron volt $(\mathrm{eV})$ or simply with the length $\lambda$ expressed in $\mathrm{nm}$ (nanometers) or Angstrom $\left(\AA=10^{-10} \mathrm{~m}\right)$ of the associated electromagnetic wave. Furthermore, the production of ion electron pairs is also conditioned by the probability of collision or interaction between a photon and a neutral atom. This is proportional not only to the intensity of radiation I, which means the number of photons, but also to the absorption cross section $\sigma_{\mathrm{f}}$ which depends on the frequency $f$ for a specific chemical component $i$. The production $q i$ is given by:[8]

$$
q_{i}=\sigma_{f} n I
$$

Where $n$ is density of the neutral particles of the element $i$.

Absolute photo-absorption cross sections using the BeerLambert law: [8]

$$
I_{t}=I_{0} \exp (-n \sigma x)
$$

Where $\mathrm{I}_{\mathrm{t}}$ is the radiation intensity transmitted through the gas sample, Io is that through the evacuated cell, $\mathrm{n}$ the molecular number density of the sample gas, $\sigma$ the absolute photoabsorption cross section, and $\mathrm{x}$ the absorption path length.

\section{Volume 6 Issue 12, December 2017}




\section{International Journal of Science and Research (IJSR) \\ ISSN (Online): 2319-7064}

Index Copernicus Value (2016): 79.57 | Impact Factor (2015): 6.391

[9]. $\mathrm{CO} 2$ is a molecule found in the earth's atmosphere, as well as in many planetary systems. The absorption of solar radiation by $\mathrm{CO} 2$ is important for determining the radiation, chemistry, and compositions of these atmospheric systems [1]. For example, as a major greenhouse gas, $\mathrm{CO} 2$ plays important roles in determining the surface temperatures of earth [10].

\section{Result and Discussion}

The solar spectrum refers to the distribution of electromagnetic radiation emitted by the sunas a function of the wavelength incident on the top of the atmosphere. The data of solar flux at the ionosphere which under quite solar conditions have been plotted as a function of wavelength. In order to study the cross section of photoabsorption and Photoionization cross section at specific wavelength ranging from (76 $\AA$ to $1200 \AA$ ) which presented the distribution of molecules at those wavelength as shown in fig (1). solar flux usually specified in units of ph. $\mathrm{cm}^{-2} \mathrm{~S}^{-1} \AA^{-1}$ but in this research $\varnothing / 10^{9} \mathrm{ph} . \mathrm{cm}^{-2} \cdot \mathrm{S}^{-1}$.These peaks shown which molecules have highest distribution are effected by solar flux change.
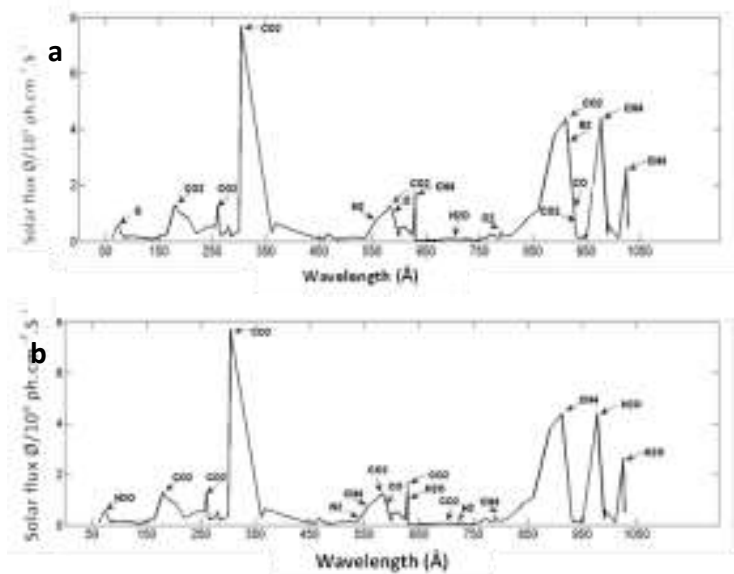

Figure 1: Solar flux $\left(\varnothing / 10^{9} \mathrm{ph} . \mathrm{cm}^{-2} . \mathrm{S}^{-1}\right)$ as function of wavelength ( $\AA$ ) for ionosphere shown: a) photoabsorption cross-section $\times 10^{18} \mathrm{~cm}^{2}$ b) distribution of photoionization cross-section $\mathrm{x} 10^{18} \mathrm{~cm}^{2}$.

From figure 1 can be shown that all elements have absorption and ionization at this rang but we take just the molecules which appear higher values of cross section at these peaks.

From figure (1) relation between solar flux and element and molecules in photoionization and photoabsorption is random. But almost molecules Recurrence is $\mathrm{CO}_{2}$ in both photoionization and photoabsorption cross section because $\mathrm{CO} 2$ has highest absorption at shorter wavelength suchfounded by Kuo C.T etc[9]. Whoever the cross section of each molecule plotted as a function of wavelength in fig (2)

From fig (2) it can be notice that all studied molecules in this paper shown on absorption and ionization processes at wavelength (76 $\AA$ to $1200 \AA$ ) but they vary in their values
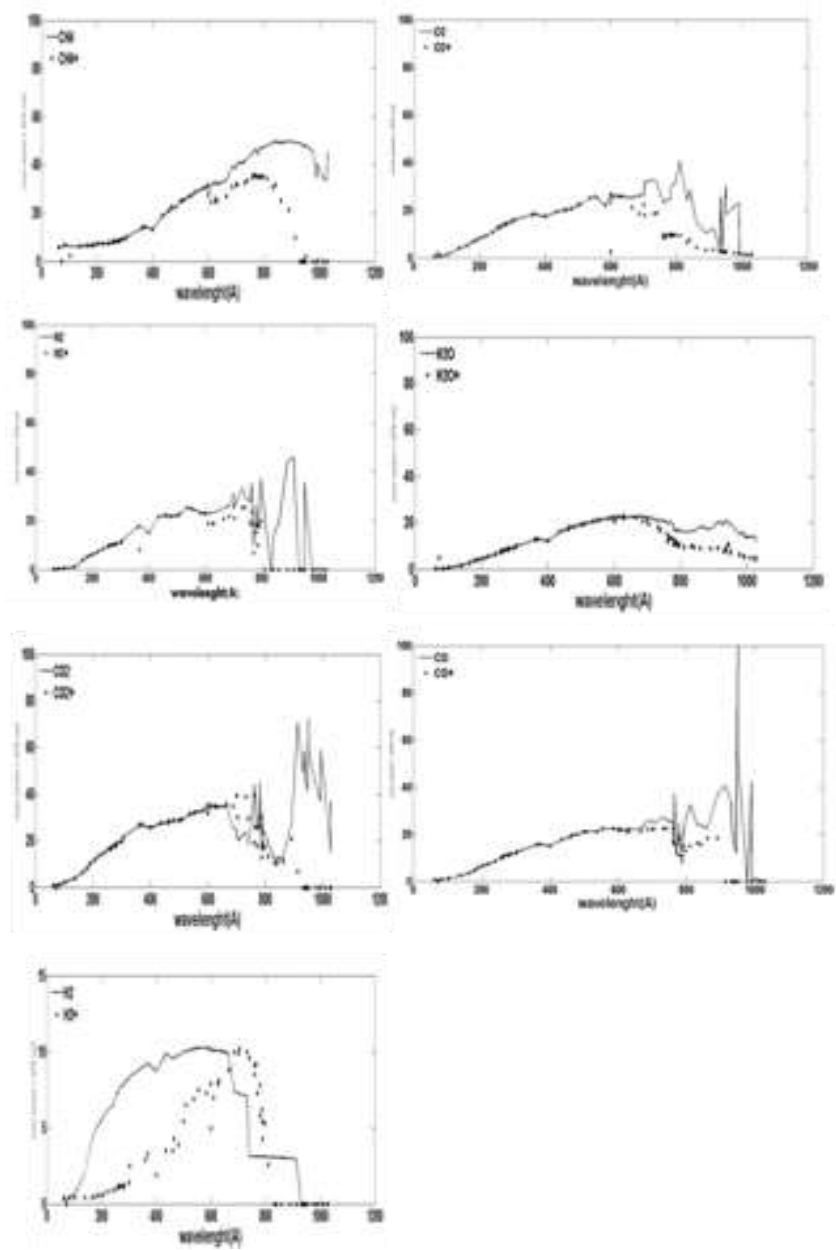

Figure 3: compare between photoabsorption and photoionization cross Section as function of wavelength $(\AA)$ for molecules $\left[\mathrm{CH}_{4}, \mathrm{O}_{2} \mathrm{~N}_{2}, \mathrm{H}_{2} \mathrm{O}, \mathrm{CO}_{2}, \mathrm{CO}\right.$ and $\left.\mathrm{H}_{2}\right]$.

This review contains a complete set of cross-section-versuswavelength values for each molecule; $\mathrm{CH}_{4}, \mathrm{O}_{2}, \mathrm{~N}_{2}, \mathrm{H}_{2} \mathrm{O}$, $\mathrm{CO}_{2}, \mathrm{CO}, \mathrm{H}_{2}$ the prepared figures are used to compare the results of several determinations or to point out where difficulties of interpretation might arise. From this compare founded that almost molecules have the same behavior in photoionization and photoabsorption cross section at $\lambda<600$ $\AA$, after that the absorption processes for chemical element become higher than ionization which become zeros at another word. But only one molecule has individual behavior in the photoabsorption and photoionization is $\mathrm{H} 2$ where the photoabsorption is wide and higher than photoionization cross section.

Table 1: The ratio of photoionization and photoabsorption for molecules in ionosphere

\begin{tabular}{|c|c|c|c|c|c|}
\hline \multicolumn{2}{|c|}{ photoabsorption } & \multicolumn{2}{|c|}{ Photoionization } & \multicolumn{2}{c|}{$\begin{array}{c}\text { Photoabsorption/ } \\
\text { photoionization }\end{array}$} \\
\hline Molecules & ratio & molecules & Ratio & Molecules & ratio \\
\hline $\mathrm{CH}_{4}$ & 0.22 & $\mathrm{CH}_{4}$ & 0.19 & $\mathrm{CH}_{4}$ & 1.15789 \\
\hline $\mathrm{O}_{2}$ & 0.13 & $\mathrm{O}_{2}$ & 0.12 & $\mathrm{O}_{2}$ & 1.08333 \\
\hline $\mathrm{N}_{2}$ & 0.11 & $\mathrm{~N}_{2}$ & 0.12 & $\mathrm{~N}_{2}$ & 0.91666 \\
\hline $\mathrm{H}_{2} \mathrm{O}$ & 0.11 & $\mathrm{H}_{2} \mathrm{O}$ & 0.12 & $\mathrm{H}_{2} \mathrm{O}$ & 0.91666 \\
\hline $\mathrm{CO}_{2}$ & 0.22 & $\mathrm{CO}_{2}$ & 0.19 & $\mathrm{CO}_{2}$ & 1.15789 \\
\hline $\mathrm{O}$ & 0.03 & $\mathrm{O}$ & 0.05 & $\mathrm{O}$ & 0.6 \\
\hline
\end{tabular}

The table shown the ratio of each molecules in photoabsorption cross section where $\mathrm{CH}_{4}$ and $\mathrm{CO}_{2}$ equal

\section{Volume 6 Issue 12, December 2017}




\section{International Journal of Science and Research (IJSR) \\ ISSN (Online): 2319-7064}

Index Copernicus Value (2016): 79.57 | Impact Factor (2015): 6.391

$0.22, \mathrm{CO}$ and $\mathrm{O}_{2}=0.13, \mathrm{~N}_{2}$ and $\mathrm{H} 2 \mathrm{O}$ equal $0.11, \mathrm{H}_{2}$ and $\mathrm{O}$ equal 0.03 .

The table shown the ratio of each molecules in photoionization cross section where $\mathrm{CH}_{4}$ and $\mathrm{CO}_{2}$ equal $0.19, \mathrm{CO}=0.13, \mathrm{~N}_{2}, \mathrm{O}_{2}$ and $\mathrm{H}_{2} \mathrm{O}$ equal $0.12, \mathrm{H}_{2}$ equal 0.03 . $\mathrm{O}=0.05$. Which notice that all ratio of molecules in total photoabsorption / total photoionization almost equal.

Table 2: The maximums value of molecules at photoabsorption and photoionization cross section

\begin{tabular}{|c|c|c|c|c|c|}
\hline \multicolumn{3}{|c|}{$\begin{array}{c}\text { Photoabsorption cross } \\
\text { section }(\sigma)\end{array}$} & \multicolumn{3}{|l|}{ Photoionization cross section $(\beta)$} \\
\hline Molecules & $\begin{array}{c}\text { Max } \\
\text { value }\end{array}$ & wavelength & Molecules & $\begin{array}{c}\text { Max } \\
\text { value }\end{array}$ & wavelength \\
\hline $\mathrm{CH}_{4}$ & 49.84 & 840 & $\mathrm{CH}_{4}$ & 35.81 & 746 \\
\hline $\mathrm{O}_{2}$ & 40.7 & 810 & $\mathrm{O}_{2}$ & 26.62 & 599 \\
\hline $\mathrm{N}_{2}$ & 46 & 912 & $\mathrm{~N}_{2}$ & 25.3 & 537 \\
\hline $\mathrm{H}_{2} \mathrm{O}$ & 22.9 & 685 & $\mathrm{H}_{2} \mathrm{O}$ & 22.5 & 629 \\
\hline $\mathrm{CO}_{2}$ & 72.5 & 949 & $\mathrm{CO}_{2}$ & 39.4 & 700 \\
\hline $\mathrm{CO}$ & 99 & 949 & $\mathrm{CO}$ & 22.2 & 584 \\
\hline $\mathrm{H}_{2}$ & 10.24 & 584 & $\mathrm{H}_{2}$ & 10.2 & 703 \\
\hline $\mathrm{O}$ & 10.24 & 584 & $\mathrm{O}$ & 10.24 & 554 \\
\hline
\end{tabular}

The table (2) show the molecules max density at which wavelength from this table note that the number of photoabsorption molecules is higher than photoionization but at higher wavelengths at another word $\sigma \neq \beta$ because the molecules can absorption the radiation such as UV and EUV without producing ionization [11].

\section{Conclusion}

1) Solar radiation is mainly absorbed in the atmosphere by $\mathrm{O} 2, \mathrm{O} 3, \mathrm{~N} 2, \mathrm{CO} 2, \mathrm{H} 2 \mathrm{O}, \mathrm{O}$, and $\mathrm{N}$, although $\mathrm{NO}, \mathrm{N} 2 \mathrm{O}$, $\mathrm{CO}$, and $\mathrm{CH} 4$, which occur in very small quantities, also exhibit absorption spectra. Absorption spectra due to electronic transitions of molecular and atomic oxygen and nitrogen, and ozone occur chiefly in the ultraviolet (UV) region

2) In general the photo absorbed is become higher at $\lambda>750$ $\mu \mathrm{m}$ where Photoionization go to zero.

3) All element oxygen (O) and molecules oxygen $\left(\mathrm{O}_{2}\right)$, nitrogen $\left(\mathrm{N}_{2}\right)$, methanol $\left(\mathrm{CH}_{4}\right)$, water $\left(\mathrm{H}_{2} \mathrm{O}\right)$, Dualdioxide $\left(\mathrm{CO}_{2}\right)$, Omnidirectional dioxide $(\mathrm{CO})$ had the same distribution expect the hydrogen $\left(\mathrm{H}_{2}\right)$ which shown too much different.

\section{Reference}

[1] R. S. Stolarsei and N. P. Johnson, "Photoionization and photoabsorption cross sections for ionospheric calculations", Journal of Atmospheric and Terrestrial Physics, (84), pp.1691-1701,1972.

[2] R.K. Vasta, and H.-R. Volpp,"Absorption cross section for ome atmospherically important molecules at the $\mathrm{H}$ atom Lyman $-\alpha$ wavelength (11.567 nm)", Chemical Physics letters (340), p.p.289-295, 2001.

[3] A.Luspay ,K.E. Mandt, J.H. Waite, and V.de. La.Haye,"The effect of photoabsorption cross section and solarflux on Ethaneproduction in Titan's Ionosphere" , Lunar and Planetary Science Conference, (44),p.p.2312, 2013.
[4] T. S. Yih, H. H. Wu, C. C. Chu, H. S. Fung, Y. P. Lin and S. J. Hsu, "Measurements of the Photoabsorption Cross-Section of Divalent Atoms", Journal of the Korean Physical Society,(32),3, p.p.405- 412,1998.

[5] R.D. Hudson, "critical Review of ultraviolet photoabsorption cross sections for molecules of Astrophysical and Aeronomic interest", Reviews of Geophysics, (9), 2, p.p. 305-406, 1971.

[6] M.H. Rees," Physics and Chemistry of the Upper Atmosphere",Cambridge University Press.2010.

[7] L. E. Archer, "Photoabsorption Spectroscopy in the Vacuum Ultraviolet: Measurements and Modeling of $\mathrm{CO}$ and $\mathrm{CO} 2$, Submitted in Partial Fulfillment of the Prerequisite for Honors in Physics, 2012

[8] B. Zolesi and L. R. Cander, Ionospheric Prediction and Forecasting, Springer Geophysics, Springer-Verlag Berlin Heidelberg, 2014.

[9] W.H. Parkinson, J. Rufus1, K. Yoshino," Absolute absorption cross section measurements of $\mathrm{CO} 2$ in the wavelength region $163-200 \mathrm{~nm}$ and the temperature dependence”, Chemical Physics,(290) p.p.251-256,2003

[10] C.T. Kuo,Y.M.Chen,S.Y.Wang,S.C.Li and J.B.Nee, "the photoabsorption spectrum of CO2 at 104-170 nm", Chinese journal of physics , (42) ,p.p65-73,2004.

[11] V. L. pisacane, "fundamental of space system", published by oxford university, 2005, 1st edition.

\section{Author Profile}

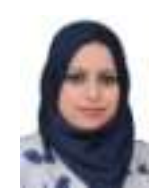

Sura I. Gburi received the B.S. and M.S. degrees in astronomy from Department of Astronomy and Space, Collage of Science, University of Baghdad in 2006 and 2012, respectively. She is teaching in Astronomy department now. 